Abstracta Iranicanica

Revue bibliographique pour le domaine irano-aryen

Volume 40-41 | 2019

Comptes rendus des publications de 2017-2018

\title{
Daryoosh Akbarzadeh, Nikolaus Schindel. A late Sasanian Hoard from Orumiyeh
}

\section{Rika Gyselen}

\section{Q OpenEdition}

1 Journals

\section{Édition électronique}

URL : http://journals.openedition.org/abstractairanica/49506

DOI : 10.4000/abstractairanica.49506

ISBN : 1961-960X

ISSN : 1961-960X

Éditeur :

CNRS (UMR 7528 Mondes iraniens et indiens), Éditions de l'IFRI

Référence électronique

Rika Gyselen, « Daryoosh Akbarzadeh, Nikolaus Schindel. A late Sasanian Hoard from Orumiyeh », Abstracta Iranica [En ligne], Volume 40-41 | 2019, document 16, mis en ligne le 30 octobre 2019, consulté le 20 avril 2021. URL : http://journals.openedition.org/abstractairanica/49506 ; DOI : https:// doi.org/10.4000/abstractairanica.49506

Ce document a été généré automatiquement le 20 avril 2021.

Tous droits réservés 


\title{
Daryoosh Akbarzadeh, Nikolaus Schindel. A late Sasanian Hoard from Orumiyeh
}

\author{
Rika Gyselen
}

\section{RÉFÉRENCE}

Daryoosh Akbarzadeh, Nikolaus Schindel. A late Sasanian Hoard from Orumiyeh. Wien: Verlag der Österreichischen Akademie der Wissenschaften, 2017, 304 p. (Sylloge Nummorum Sasanidarum Iran)

1 Le trésor monétaire de Orumiyeh fut trouvé en 2007 dans la région de Piran-Shahr dans le nord-ouest de l'Iran et comporte 1267 monnaies d'argent allant du règne de Khusraw Ier (530-5) au début de l'Islam.

2 Toutes les monnaies ont été consignées dans un catalogue sous forme de sylloge (p. 76-295), suivi d'index des rois et des ateliers monétaires (p. 297-298), une liste d'abréviations et la bibliographie.

3 La première partie de l'ouvrage comporte une discussion sur la composition du trésor et une étude comparative avec une vingtaine d'autres trésors monétaires d'époque sassanide tardive ou post-sassanide. On ne peut que se réjouir que cent vingt $\mathrm{drahm}$ aient été analysées par XRF analyse de la surface. Quelques questions récurrentes sont évoquées: la très faible production monétaire à l'an 18 du règne de Khusraw II ; la présence sur certains drahm de la formule $a b d$ « merveilleux ». Ces aspects ont déjà été discutés maintes fois sans qu'aucune explication unanimement acceptée n'ait été apportée. 


\section{AUTEURS}

\section{RIKA GYSELEN}

CNRS, Mondes iranien et indien 